\title{
Pharmacokinetic study of weekly administration dose of paclitaxel in patients with advanced or recurrent gastric cancer in Japan
}

\author{
Michiya Kobayashi ${ }^{1}$, Koji Oba ${ }^{2}$, Junichi Sakamoto ${ }^{3}, \mathrm{Ken} \mathrm{Kondo}^{4}$, Naoki Nagata ${ }^{5}$, Takehiro Okabayashi ${ }^{6}$, \\ Tsutomu NamiKaWA ${ }^{6}$, and KazUhiro HanAZAKi ${ }^{6}$ \\ ${ }^{1}$ Department of Human Health and Medical Sciences, Kochi Medical School, Oko-cho, Nankoku 783-8505, Japan \\ ${ }^{2}$ Department of Epidemiological and Clinical Research Information Management, Kyoto University, Kyoto, Japan \\ ${ }^{3}$ Young Leaders Program, Nagoya University Graduate School of Medicine, Nagoya, Japan \\ ${ }^{4}$ Department of Surgery, Nagoya National Hospital, Nagoya, Japan \\ ${ }^{5}$ First Department of Surgery, University of Occupational and Environmental Health, Kitakyushu, Japan \\ ${ }^{6}$ Department of Surgery, Kochi Medical School, Nankoku, Japan
}

\begin{abstract}
Background. We aimed to clarify the relationship between the maximum tolerated dose and plasma concentration of paclitaxel in Japanese patients with gastric cancer on a weekly paclitaxel administration regimen.

Methods. Thirty-three patients with advanced or recurrent gastric cancer were treated with escalating doses of paclitaxel, administered weekly, along with a fixed dose of 5-fluorouracil or cisplatin.

Results. The plasma concentration of paclitaxel remained above $8.5 \mathrm{ng} / \mathrm{ml}$ for $24 \mathrm{~h}$ after administration. The mean area under the curve increased significantly with escalating dosage levels $(R=0.63 ; P<0.001)$. At level 4 , patients showing doselimiting toxicity had a significantly higher plasma paclitaxel concentration than patients without it.

Conclusion. The weekly administration of paclitaxel, for which a single dose is about one-third of the dose for a triweekly treatment regimen, is clinically feasible and appropriate in terms of toxicity and the maintenance of an effective plasma concentration.
\end{abstract}

Key words Paclitaxel · Chemotherapy · Gastric cancer · Pharmacokinetic study · Advanced gastric cancer

\section{Introduction}

Paclitaxel (PTX), originally isolated from the bark of the tree Taxus brevifolia, is a potent inhibitor of cell replication. The antimitotic activity of PTX results from its ability to block the late G2 and M phases of the cell cycle. PTX has significant antitumor activity in several human tumors, including advanced ovarian, lung, and breast cancers [1]. Chang et al. [2] demonstrated that
PTX inhibited the growth of gastric carcinoma cell lines at clinically attainable concentrations. Several reports describe the effectiveness of PTX in combination chemotherapy with 5-fluorouracil (5-FU) or cisplatin in the treatment of advanced gastric cancer [3-8].

In preclinical studies, the growth inhibitory effect of PTX on primary cultures of gastric cancer was greater than that of other anticancer agents [9]. Therefore, PTX administration is expected to provide a clinical advantage in the treatment of gastric cancer. In a phase II trial of PTX administration by 3-h infusion every 3 weeks for patients with gastric cancer, a $23 \%$ response rate was observed [8]. Weekly administration of PTX has been demonstrated to be well-tolerated and feasible in patients with ovarian cancer [10], breast cancer [11], and lung cancer [12]. Furthermore, PTX exerts its cytotoxic effects through a mechanism different from that of cisplatin and 5-FU, and shows no cross-resistance with cisplatin [13-15]. The recommended optimal dose of cisplatin was determined to be more than $20 \mathrm{mg} / \mathrm{m}^{2}$ per week $[13,14]$.

Based on these reports, we conducted two phase I clinical studies of combination chemotherapy investigating escalating weekly doses of PTX in patients with advanced or metastatic gastric cancer in Japan. One study included fixed systemic administration of 5-FU for 18 patients and the other included fixed systemic administration of cisplatin for 15 patients. A pharmacokinetic study of PTX was performed to clarify the relationship between dose-limiting toxicity (DLT) and serum PTX concentration. 


\section{Patients, materials, and methods}

\section{Eligibility}

Patients in this study had histologically proven metastatic gastric cancer with/without measurable lesions. Other inclusion criteria were: age 20 to 75 years, Eastern Cooperative Oncology Group (ECOG) performance status less than 2, life expectancy more than 2 months, adequate bone marrow function (white cell count $>4000 / \mathrm{mm}^{3}$, platelet count $>100000 / \mathrm{mm}^{3}$, and hemoglobin level $>9.0 \mathrm{~g} / \mathrm{dl}$ ), adequate renal function (creatinine clearance $>50 \mathrm{ml} / \mathrm{min}$ ), adequate hepatic function (bilirubin level $<1.5 \mathrm{mg} / \mathrm{dl}$ and GOT, GPT $<$ twice the upper limit of normal), more than a 1-month interval since prior chemotherapy, and no active cancer in other organs. All patients gave written informed consent conforming to institutional guidelines indicating that they were aware of the investigational nature of the study. This protocol was approved by the ethics committees of all participating institutions.

\section{Treatment}

In study 1 , a fixed dose of $600 \mathrm{mg} / \mathrm{m}^{2}$ per day of 5 -FU was administered by continuous infusion for 5 days on days $1-5$ and PTX was infused for $1.5 \mathrm{~h}$ on days 8,15 , and 22. In study 2, PTX was infused for $1.5 \mathrm{~h}$ on days 1 , 8 , and 15 following the infusion of a fixed dose of $25 \mathrm{mg} /$ $\mathrm{m}^{2}$ cisplatin for $2 \mathrm{~h}$. In both studies, PTX was administered after standard prophylactic pretreatment for PTX-associated hypersensitivity reactions, using dexamethasone (20 mg i.v.), diphenhydramine ( $25 \mathrm{mg}$ p.o.), and ranitidine (50 mg i.v.). The PTX dose was escalated in successive patient cohorts to determine the maximum tolerated dose (MTD). The doses of PTX were as follows: dose level 1 (starting dose), $60 \mathrm{mg} / \mathrm{m}^{2}$; dose level $2,70 \mathrm{mg} / \mathrm{m}^{2}$; dose level $3,80 \mathrm{mg} / \mathrm{m}^{2}$; and dose level 4 , $90 \mathrm{mg} / \mathrm{m}^{2}$. Dose escalation was not performed until safety and tolerance had been assessed at the previous dose level.

Determination of the MTD for paclitaxel was performed by evaluating individual cohorts of three to six patients at each dose level. If the first three patients did not develop DLT at a given dose, the dose was escalated to the next level in a subsequent cohort. If one of the first three patients developed DLT, an additional three patients were recruited and given the same dose level. The PTX dose was escalated only if fewer than two of these additional three patients developed DLT. If two or more out of a cohort of three, or three or more out of a cohort of six patients developed DLT, then accrual of patients at that level of PTX was stopped, and that level was designated the MTD. No intrapatient dose escalation was performed.

\section{Toxicity}

During treatment, patients had weekly full hematological blood cell counts, determination of liver and renal function, and assessment of nonhematological toxicities. Toxicity, according to National Cancer Institute common toxicity criteria (NCI-CTC) [16], was recorded every week. Dose-limiting hematological and nonhematological toxicities were defined separately. Doselimiting hematological toxicities were defined as NCI grade 4 leukopenia or grade 4 neutropenia lasting for more than 4 days, grade 3 leukopenia or grade 3 neutropenia accompanied by high fever $\left(>38^{\circ} \mathrm{C}\right)$, and grade 4 thrombocytopenia $\left(<25000 / \mathrm{mm}^{3}\right)$. Dose-limiting nonhematological toxicities were defined as NCI grade 3 and 4 toxicity, with specific exclusion of grade 3 nausea, vomiting, or alopecia.

\section{Pharmacokinetic study}

Table 1 shows the characteristics of the patients included in both studies. In study 1, PTX dose levels 1, 2,

Table 1. Patient characteristics

\begin{tabular}{lcc}
\hline & Study $1(n=18)$ & Study $2(n=15)$ \\
\hline Sex & & \\
M & 11 & 11 \\
F & 7 & 4 \\
Mean age (years) & $58.7(22-75)$ & $63.1(38-74)$ \\
Histology & & \\
Well & 1 & 0 \\
Mod & 6 & 5 \\
Por & 6 & 6 \\
Sig & 1 & 4 \\
Pap & 1 & 0 \\
Site & & \\
Lymph node & 5 & 8 \\
Peritoneum & 6 & 2 \\
Liver & 2 & 1 \\
Lung & 1 & 0 \\
Stomach & 4 & 1 \\
Pancreas & 0 & 0 \\
Diaphragm & 1 & 8 \\
PS & & 7 \\
0 & 5 & 0 \\
1 & 9 & 3 \\
2 & 1 & 3 \\
Dose level (DLT) & $6(1)$ & \\
1 & 3 & \\
2 & $6(2)$ & \\
3 & & \\
4 & & \\
\hline
\end{tabular}

Well, well-differentiated tubular adenocarcinoma; mod, moderately differentiated tubular adenocarcinoma; por, poorly differentiated adenocarcinoma; sig, signet-ring cell carcinoma; pap, papillary adenocarcinoma; PS, Eastern Cooperative Oncology Group (ECOG) performance status [25]

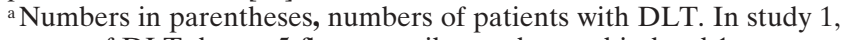
a case of DLT due to 5-fluorouracil was observed in level 1 
3 , and 4 were given to $6,3,6$, and 3 patients, respectively. In study 2, each PTX dose level was given to 3, 3,3 , and 6 patients, respectively.

Blood samples were collected in heparinized tubes before PTX administration and at 0, 0.5, 1.5, 6, 12, and $24 \mathrm{~h}$ after completion of PTX administration during the initial treatment course. The samples were then centrifuged, and the supernatant was stored at $-20^{\circ} \mathrm{C}$ until required for assay. Paclitaxel (PTX) concentrations were measured by a reverse-phase high-performance liquid chromatographic assay [17]. The area under the concentration-time curve (AUC) was calculated by the trapezoid rule.

\section{Statistical analysis}

Pharmacokinetic parameters, the AUC and the plasma concentration, were reported as mean values $\pm \mathrm{SD}$, unless stated otherwise. Differences in the means of peak plasma concentrations (Cmax) and AUC between dosage levels were analyzed for significance using a twotailed $t$-test. The relationships between the AUC and the dosage level and those between Cmax and the dosage level were analyzed by means of a Spearman's rank correlation coefficient. A $P$ value of less than 0.05 was considered to be statistically significant.

\section{Results}

In study 1 , there was one case of DLT at PTX dosage level 1, shown to be caused by 5-FU, and not PTX, by the Data-Monitoring Committee, because the patient showed grade 3 diarrhea prior to PTX administration. There were two cases of DLT at PTX dosage level 3 (grade 3 stomatitis and grade 3 diarrhea) and two at level 4 (grade 3 diarrhea, grade 3 hyperbilirubinemia, and grade 3 hyponatremia in one patient, and grade 4 leucopenia, grade 4 neutropenia, grade 4 hyperbilirubinemia, and grade 4 liver dysfunction in another patient) in study 1 . There were also two cases of DLT at PTX dosage level 4 in study 2 (grade 4 leukopenia and grade 4 neutropenia in both patients; Table 1).

The mean plasma concentrations of PTX are shown in Table 2. After completion of administration, the plasma PTX concentration reached a peak, and then decreased rapidly for $1.5 \mathrm{~h}$ before continuing to decrease more gradually. Plasma PTX concentrations were maintained above $8.5 \mathrm{ng} / \mathrm{ml}$ for $24 \mathrm{~h}$ after PTX administration. Our pharmacokinetic study showed that the plasma PTX concentration was maintained in all patients for at least $24 \mathrm{~h}$ between the level required to effectively target cancer cells and the dose cytotoxic to normal cells (Fig. 1).

Table 2. Mean plasma concentration $(\mathrm{ng} / \mathrm{ml}) \pm \mathrm{SD}$ of PTX after administration of PTX at each dose level

\begin{tabular}{|c|c|c|c|c|c|c|}
\hline Hours & 0 & 0.5 & 1.5 & 6 & 12 & 24 \\
\hline Level $1\left(60 \mathrm{mg} / \mathrm{m}^{2}\right)$ & $1205 \pm 466.6$ & $315.4 \pm 109.9$ & $146.0 \pm 38.6$ & $64.7 \pm 15.2$ & $40.4 \pm 11.2$ & $21.4 \pm 5.5$ \\
\hline Level $2\left(70 \mathrm{mg} / \mathrm{m}^{2}\right)$ & $1747.7 \pm 822.7$ & $594.3 \pm 326.6$ & $206.0 \pm 47.6$ & $81.7 \pm 16.2$ & $55.0 \pm 21.1$ & $27.8 \pm 7.0$ \\
\hline Level $3\left(80 \mathrm{mg} / \mathrm{m}^{2}\right)$ & $1482.4 \pm 574.1$ & $440.4 \pm 168.6$ & $219.4 \pm 97.9$ & $93.0 \pm 52.7$ & $54.4 \pm 24.8$ & $34.3 \pm 16.9$ \\
\hline Level $4\left(90 \mathrm{mg} / \mathrm{m}^{2}\right)$ & $2328.3 \pm 754.3$ & $832.1 \pm 619.0$ & $374.2 \pm 169.8$ & $146.4 \pm 82.0$ & $85.8 \pm 55.4$ & $46.4 \pm 23.8$ \\
\hline
\end{tabular}

Levels 1, 2, 3, and 4 had 9, 6, 9, and 9 patients, respectively

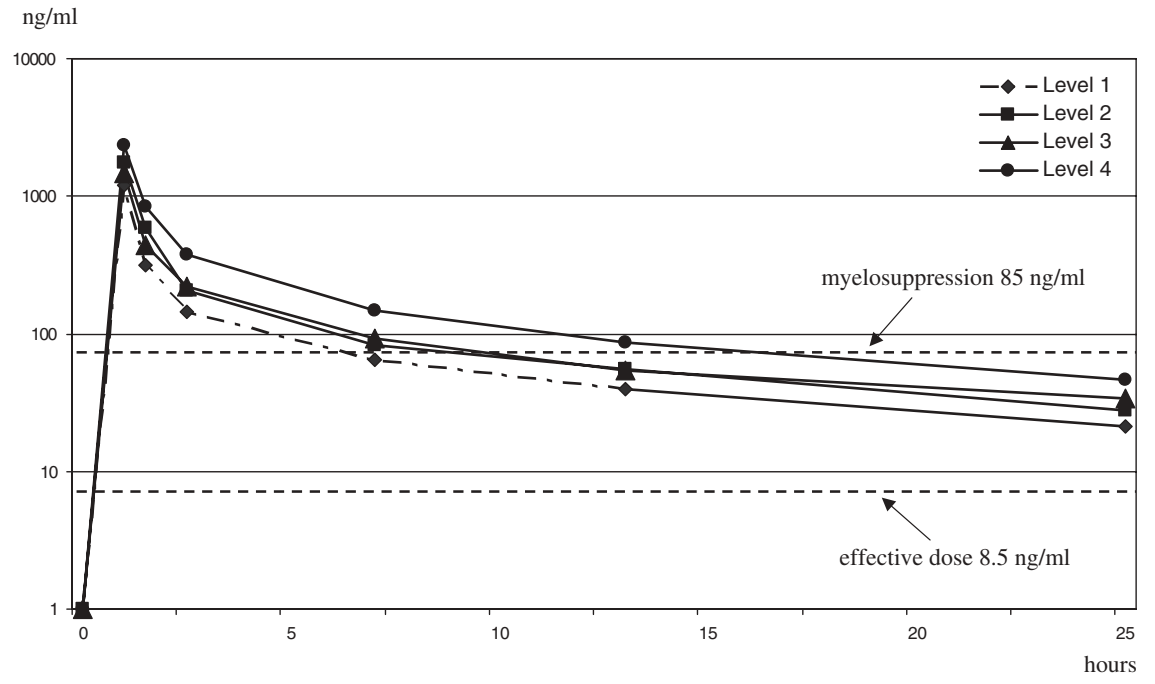

Fig. 1. Plasma concentration of paclitaxel (PTX) at each dose level 
The mean AUCs for each PTX dose level were 2753.7 $\pm 617.6 \mathrm{ng} \cdot \mathrm{h} / \mathrm{ml}$ for level $1\left(60 \mathrm{mg} / \mathrm{m}^{2}\right), 3912.6 \pm$ $1188.6 \mathrm{ng} \cdot \mathrm{h} / \mathrm{ml}$ for level $2\left(70 \mathrm{mg} / \mathrm{m}^{2}\right), 4236.1 \pm 1972.5 \mathrm{ng} \cdot \mathrm{h} /$ $\mathrm{ml}$ for level $3\left(80 \mathrm{mg} / \mathrm{m}^{2}\right)$, and $5981.3 \pm 2272.2 \mathrm{ng} \cdot \mathrm{h} / \mathrm{ml}$ for level $4\left(90 \mathrm{mg} / \mathrm{m}^{2}\right)$. The mean AUC increased with escalating paclitaxel dosage levels $(R=0.63, P<0.001$; Table 3). The mean Cmax values of PTX for dosage levels $1,2,3$, and 4 were $1205.0 \pm 466.6 \mathrm{ng} / \mathrm{ml}, 1747.7 \pm$ $822.7 \mathrm{ng} / \mathrm{ml}, 1482.4 \pm 574.1 \mathrm{ng} / \mathrm{ml}$, and $2328.3 \pm 754.3 \mathrm{ng} /$ $\mathrm{ml}$, respectively (Table 3 ). The Cmax was also dosedependent and increased with escalating paclitaxel dosage levels $(R=0.51, P=0.002)$. There were no significant

Table 3. Mean AUC (ng.h/ml) \pm SD of PTX and peak plasma PTX level (Cmax) at each dose level

\begin{tabular}{lll}
\hline & AUC $(\mathrm{ng} \cdot \mathrm{h} / \mathrm{ml})$ & Cmax $(\mathrm{ng} / \mathrm{ml})$ \\
\hline Level 1 $\left(60 \mathrm{mg} / \mathrm{m}^{2}\right)$ & $2753.7 \pm 617.6$ & $1205.0 \pm 466.6$ \\
Level 2 $\left(70 \mathrm{mg} / \mathrm{m}^{2}\right)$ & $3912.6 \pm 1188.6$ & $1747.7 \pm 822.7$ \\
Level 3 $\left(80 \mathrm{mg} / \mathrm{m}^{2}\right)$ & $4236.1 \pm 1972.5$ & $1482.4 \pm 574.1$ \\
Level 4 $\left(90 \mathrm{mg} / \mathrm{m}^{2}\right)$ & $5981.3 \pm 2272.2$ & $2328.3 \pm 754.3$
\end{tabular}

Both the mean AUC and Cmax increased with escalating paclitaxel dosage levels (AUC, $R=0.63 ; P<0.001$; $\max , R=0.51 ; P=0.002$ ) differences in AUC or Cmax values between the two studies and the correlations between dose level and AUC and dose level and Cmax were similar (AUC, $R$ $=0.63$ in study $1 ; P=0.005 ; R=0.59$ in study $2 ; P=0.020$; Cmax, $R=0.52$ in study $1 ; P=0.026 ; R=0.48$ in study 2; $P=0.073)$, though the combined drug and the timing of PTX administration were different (Tables 4, 5).

Table 6 shows the plasma PTX concentrations for patients with and without DLT at PTX dosage levels 3 and 4. For level 3, the mean AUC value estimated for patients with DLT was $4286.4 \pm 2998.5 \mathrm{ng} \cdot \mathrm{h} / \mathrm{ml}$, while for patients without DLT the mean AUC value was $4221.8 \pm 1920.5 \mathrm{ng} \cdot \mathrm{h} / \mathrm{ml}$. These values were not significantly different $(P=0.4853)$. By comparison, the mean AUC values for patients with and without DLT at PTX dosage level 4 were significantly different $(P=0.03)$, at $7703.2 \pm 2391.8 \mathrm{ng} \cdot \mathrm{h} / \mathrm{ml}$ and $4603.8 \pm 836.0 \mathrm{ng} \cdot \mathrm{h} / \mathrm{ml}$, respectively. Hematological toxicity was observed in three patients given PTX dosage level 4. The mean AUC of these patients was $8461.1 \pm 2266.0 \mathrm{ng} \cdot \mathrm{h} / \mathrm{ml}$, which was significantly higher than the mean AUC value of 4603.8 $\pm 836.0 \mathrm{ng} \cdot \mathrm{h} / \mathrm{ml}$ for patients without DLT at PTX dosage level $4(P=0.01$; Table 6$)$.

Table 4. Mean AUC (ng.h/ml) \pm SD of PTX in each study

\begin{tabular}{lccr}
\hline AUC $(\mathrm{ng} \cdot \mathrm{h} / \mathrm{ml})$ & Study $1 *$ & Study $2 * *$ & \multicolumn{1}{c}{$\begin{array}{c}\text { Difference } \\
(P \text { value })\end{array}$} \\
\hline Level 1 $\left(60 \mathrm{mg} / \mathrm{m}^{2}\right)$ & $2534.9 \pm 567.9$ & $3191.4 \pm 537.2$ & $-656.5(0.14)$ \\
Level 2 $\left(70 \mathrm{mg} / \mathrm{m}^{2}\right)$ & $3631.6 \pm 1208.6$ & $4193.7 \pm 1354.3$ & $-562.1(0.62)$ \\
Level $3\left(80 \mathrm{mg} / \mathrm{m}^{2}\right)$ & $4444.8 \pm 2370.1$ & $3818.9 \pm 1062.4$ & $625.9(0.68)$ \\
Level $4\left(90 \mathrm{mg} / \mathrm{m}^{2}\right)$ & $6511.7 \pm 2946.3$ & $5716.2 \pm 2129.7$ & $795.5(0.65)$ \\
\hline
\end{tabular}

* Study 1: $R=0.63 ; P=0.005$

** Study $2: R=0.59 ; P=0.020$

Table 5. Peak plasma PTX level (Cmax) in each study

\begin{tabular}{lccr}
\hline Cmax $(\mathrm{ng} / \mathrm{ml})$ & Study 1* & Study 2** & \multicolumn{1}{c}{$\begin{array}{r}\text { Difference } \\
(P \text { value })\end{array}$} \\
\hline Level 1 $\left(60 \mathrm{mg} / \mathrm{m}^{2}\right)$ & $1119.3 \pm 471.0$ & $1376.3 \pm 500.3$ & $-257(0.47)$ \\
Level 2 $\left(70 \mathrm{mg} / \mathrm{m}^{2}\right)$ & $1751.7 \pm 857.5$ & $1743.7 \pm 978.1$ & $8(0.99)$ \\
Level 3 $\left(80 \mathrm{mg} / \mathrm{m}^{2}\right)$ & $1453.7 \pm 479.8$ & $1540.0 \pm 857.5$ & $-86.3(0.85)$ \\
Level 4 $\left(90 \mathrm{mg} / \mathrm{m}^{2}\right)$ & $2156.7 \pm 172.1$ & $2414.2 \pm 933.8$ & $-257.5(0.66)$ \\
\hline *Study 1: $R=0.52 ; P=0.026$ & & \\
**Study 2: $R=0.48 ; P=0.073$ & &
\end{tabular}

Table 6. Mean AUC (ng.h/ml) of patients with and without DLT at PTX levels 3 and 4

\begin{tabular}{|c|c|c|c|}
\hline & $\operatorname{DLT}(-)$ & $\operatorname{DLT}(+)$ & $\begin{array}{c}\text { Hematological } \\
\text { toxicity }\end{array}$ \\
\hline Level 3a $\left(80 \mathrm{mg} / \mathrm{m}^{2}\right)$ & $4221.8 \pm 1920.5(n=7)$ & $4286.4 \pm 2998.5(n=2)$ & - \\
\hline Level $4^{\mathrm{b}}\left(90 \mathrm{mg} / \mathrm{m}^{2}\right)$ & $4603.8 \pm 836.0 \quad(n=5)$ & $7703.2 \pm 2391.8(n=4)$ & $8461.1 \pm 2266.0(n=3)$ \\
\hline
\end{tabular}




\section{Discussion}

Gastric cancer is one of the most common cancers in Japan. Although advances in early diagnosis and surgical techniques have improved the outcome of treatment for gastric cancer, optimal chemotherapy regimens have not been determined for advanced or recurrent gastric cancer.

Several phase I and phase II studies have demonstrated response rates of $40 \%$ to $80 \%$ for patients with advanced-stage gastric cancers $[18,19]$. In Western countries, to date, commonly used regimens include EAP (etoposide/doxorubicin/cisplatin) [3], FAP(5-FU/ doxorubicin/cisplatin) [4], and FP (5-FU/cisplatin) [5]. In Japan, continuous 5-FU infusion is generally accepted as the standard treatment for patients with advancedstage gastric cancers, based on survival rates and toxicity [20]. The newly developed oral fluorinated pyrimidine drug, TS-1, is now widely accepted as a first-line treatment for advanced gastric cancers in Japan. Despite the many clinical trials to determine the effectiveness of various chemotherapy regimens, a universally accepted, standard treatment regimen for recurrent or advanced gastric cancer has not yet been established.

Combination chemotherapy studies of the newly developed anticancer agent, PTX, have been conducted, and a phase II clinical study has shown PTX to be effective in treating progressive cancer in $23.3 \%$ of patients and useful in $26.9 \%$ of patients who had received prior chemotherapy $[8,21]$. In these phase II studies, the intravenous administration of PTX every 3 weeks for $3 \mathrm{~h}$ at a dose of $210 \mathrm{mg} / \mathrm{m}^{2}$ resulted in adverse effects such as peripheral neuropathy and myalgia. By comparison, weekly administration of PTX was shown to reduce the toxicity but not the efficacy of PTX [22].

Recently, patients with advanced gastric cancer have been treated by weekly administration of PTX. According to Norton's dose-density concept, weekly administration of PTX is expected to have a stronger anticancer effect, with reduced toxicity, compared to a tri-weekly single-administration schedule [23]. The effectiveness of weekly administration of PTX is most likely due to the maintenance of plasma concentrations that are cytotoxic to cancer cells [2,24].

The two phase I studies of PTX combination chemotherapy described in the present report revealed a recommended weekly dose for PTX of $80 \mathrm{mg} / \mathrm{m}^{2}$. Both the AUC and the Cmax were dose-dependent and increased with escalating paclitaxel dosage levels. The drugs combined with PTX differed in the two studies, and therefore the plasma concentration of PTX may have been influenced differently. However, there have been no reports regarding a relationship between PTX and 5-FU or cisplatin. Blood samples for the pharmacokinetic study were taken during the initial treatment course.
This may have reduced the influence of the combined drugs. The statistical investigation showed that there were no significant differences in AUC or Cmax between our two studies, and the correlations between dose level and AUC and dose level and Cmax were similar. The mean AUC was significantly higher for patients with DLT than those without DLT in level 4, but this was not so in level 3. These results demonstrate that the recommended weekly dose of $80 \mathrm{mg} / \mathrm{m}^{2}$ PTX is appropriate and confirm our estimations of the MTD and DLT values for PTX.

One of our patients, not included in the studies described in this report, received $60 \mathrm{mg} / \mathrm{m}^{2}$ PTX and had serum PTX levels measured $60 \mathrm{~h}$ after PTX administration. Another patient, from study 2, given a level 3 PTX dose, had serum PTX levels measured 168h after PTX administration. Data from these two patients revealed that plasma levels of PTX remained within the effective range for 60 and $72 \mathrm{~h}$, respectively (data not shown, submitted for publication).

In conclusion, the weekly administration of PTX, for which the single dose is about one-third of the standard dose required for a tri-weekly treatment regimen, is clinically feasible and appropriate in terms of toxicity and the maintenance of an effective plasma concentration.

Acknowledgments This study was supported by Kobayashi Magobe Memorial Medical Foundation and Epidemiological and Clinical Research Information Network.

\section{References}

1. Rowinsky EK, Donehower RC. Paclitaxel (Taxol). N Engl J Med 1995;332:1004-14.

2. Chang Y-F, Li LL, Wu C-W, Liu W-Y, P'eng F-K, Chi C-W. Paclitaxel-induced apoptosis in human gastric carcinoma cell lines. Cancer 1996;77:14-8.

3. Kim HY, Shin SW, Kim BS, Kim JH, Kim JG., Mok YJ, et al. Paclitaxel, 5-fluorouracil, and cisplatin combination chemotherapy for the treatment of advanced gastric carcinoma. Cancer 1999;85:295-301.

4. Murad AM, Petroianu A, Guimaraes RC, Aragao BC, Cabral LOM, Scalabrini-Neto AO. Phase II trial of the combination of paclitaxel and 5-fluorouracil in the treatment of advanced gastric cancer. A novel, safe, and effective regimen. Am J Clin Oncol 1999;22:580-6.

5. Lokich JJ, Sonneborn H, Anderson NR, Bern, MM, Coco, FV, Dow E, Oliynyk P. Combined paclitaxel, cisplatin, and etoposide for patients with previously untreated esophageal and gastroesophageal carcinomas. Cancer 1999;85:2347-51.

6. Kollmannsberger C, Quietzsch D, Haag C, Lingenfelser T, Schroeder M, Hartmann JT, et al. A phase II study of paclitaxel, weekly, 24-hour continuous infusion 5-fluorouracil, folinic acid and cisplatin in patients with advanced gastric cancer. Br J Cancer 2000;83:458-62.

7. Garcia AA, Leichman CG, Lenz HJ, Baranda J, Lujan R, Casagrande Y, Leichman L. Phase II trial of outpatient schedule of 
paclitaxel in patients with previously untreated metastatic, measurable adenocarcinoma of the stomach. Jpn J Clin Oncol 2001;31: 275-8.

8. Yamada Y, Shirao K, Ohtsu A, Boku N, Hyodo I, Miyata Y, Taguchi T. Phase II trial of paclitaxel by 3-hour infusion for advanced gastric cancer with short premedication for prophylaxis against paclitaxel-associated hypersensitivity reactions. Ann Oncol 2001;12:1133-7.

9. Matsuoka H, Yano K, Saito Y, Tomoda H. Cytotoxicity of paclitaxel in comparison with other anticancer agents against neoplastic cells obtained from clinical gastrointestinal carcinoma tissue. Anticancer Res 1995;15:2001-6.

10. Fennelly D, Aghajanian C, Shapiro F, O'Flaherty C, McKenzie M, O'Connor C, et al. Phase I and pharmacologic study of paclitaxel administered weekly in patients with relapsed ovarian cancer. J Clin Oncol 1997;15:187-92.

11. Klaassen U, Wilke H, Stumberg D, Eberhardt W, Korn M, Seeber S. Phase I study with a weekly 1-h infusion of paclitaxel in heavily pretreated patients with metastatic breast and ovarian cancer. Eur J Cancer 1996;32A:547-9.

12. Segawa Y, Watanabe K, Hiraki S, Tominaga K, Hayashi I, Harada M, et al. Phase I study of docetaxel and cisplatin for patients with previously untreated metastatic non-small-cell lung cancer: a Japanese cooperative study. Int J Clin Oncol 2000;5: 308-15.

13. Kano Y, Akutsu M, Tsunoda S, Matsui J, Suzuki K, Ikeda T, et al. Schedule-dependent interaction between paclitaxel and 5fluorouracil in human carcinoma cell lines in vitro. Br J Cancer 1996;74:704-10.

14. Shimon R, Karn EL. Selecting drug combinations based on total equivalent dose (dose intensity). J Natl Cancer Inst 1990;82: 1469-76.

15. Pronzato P, Bertelli G, Vigani A, Vaira F. A feasibility study of accelerated polychemotherapy with cisplatin, epidoxorubicin, and cyclophosphamide (PEC) in advanced ovarian cancer. $\mathrm{Br} \mathbf{J}$ Cancer 1996;73:1425-7.

16. National Cancer Institute. NCI common toxicity criteria, version 1. In: Investigators handbook: a manual of participants in clinical trials of investigational agents, sponsored by the Division of Cancer Treatment, National Cancer Institute. Bethesda, MD: U.
S. Department of Health and Human Services, Public Health Service, National Institute of Health; 1993.

17. Wiernik PH, Schwartz EL, Einzig A, Strauman JJ, Lipton RB, Cutcher JP. Phase I trial of taxol given as a 24-hour infusion every 21 days: responses observed in metastatic melanoma. J Clin Oncol 1987;5:1232-9.

18. Vanhoefer U, Rougier P, Wilke H, Ducreux MP, Lacave AJ, Van Cutsem E, et al. Final result of a randomized phase III trial of sequential high-dose methotrexate, fluorouracil, and doxorubicin versus etoposide, leucovorin, and fluorouracil versus infusional fluorouracil and cisplatin in advanced gastric cancer: a trial of the European Organization for Research and Treatment of Cancer Gastrointestinal Tract Cancer Cooperative Group. J Clin Oncol 2000;18:2648-57.

19. Ohtsu A, Shimada Y, Yoshida S, Saito H, Seki S, Morise K, Kurihara M. Phase II study of protracted infusional 5-fluorouracil combined with cisplatinum for advanced gastric cancer: report from the Japan Clinical Oncology Group (JCOG). Eur J Cancer 1994;30A:2091-3.

20. Shimada Y, Shirao K, Ohtsu A, Hyodo I, Saito H, Yamamichi N, et al. Phase III study of UFT + MMC versus 5-FU + CDDP versus 5-FU alone in patients with advanced gastric cancer. JCOG study 9205 (abstract). Proc ASCO 1999;18:272.

21. Yamaguchi K, Tada M, Horikoshi N, Otani T, Takiuchi H, Saitoh $\mathrm{S}$, et al. Phase II study of paclitaxel with 3 -h infusion in patients with advanced gastric cancer. Gastric Cancer 2002;5:90-5.

22. Rosenberg P, Anderson H, Boman K, Ridderheim M, Sorbe B, Puistola U, Horvath G. A randomized multicenter study of single agent paclitaxel given weekly versus every 3 weeks to patients with ovarian cancer previously treated with platinum therapy (abstract). Proc ASCO 1999;18:368a.

23. Norton L. Theoretical concepts and the emerging role of taxanes in adjuvant therapy. Oncologist 2001;6 (Suppl 3):30-5.

24. Glantz MJ, Choy H, Akerley W, Kearns CM, Egorin MJ, Rhodes $\mathrm{CH}$, Cole BF. Weekly paclitaxel with and without concurrent radiation therapy: toxicity, pharmacokinetics, and response. Semin Oncol 1996;23 (6 Suppl 16):128-35.

25. Oken MM, Creech RH, Tormey DC, Horton J, Davis TE, McFadden ET, et al. Toxicity and response criteria of the Eastern Cooperative Oncology Group. Am J Clin Oncol 1982;6:649-55. 